\title{
PHOTOSYNTHETIC THERMAL TOLERANCE AND RECOVERY TO SHORT \\ DURATION TEMPERATURE STRESS IN DESERT AND MONTANE PLANTS: A COMPARATIVE STUDY
}

\author{
A Thesis \\ presented to \\ the Faculty of California Polytechnic State University, \\ San Luis Obispo
}

\author{
In Partial Fulfillment \\ of the Requirements for the Degree \\ Master of Science in Biology
}

by

David William Gallagher

May 2014 
(C) 2014

David William Gallagher

ALL RIGHTS RESERVED 


\section{COMMITTEE MEMBERSHIP}

TITLE:

AUTHOR:

DATE SUBMITTED:

COMMITTEE CHAIR:

COMMITTEE MEMBER:

COMMITTEE MEMBER:
Photosynthetic thermal tolerance and recovery to short duration temperature stress in desert and montane plants: A comparative study

David William Gallagher

May 2014

Charles Knight, PhD

Associate Professor of Biology

Matt Ritter, $\mathrm{PhD}$

Professor of Biology

Scott Steinmaus, PhD

Professor and Interim Horticulture and Crop Science Department Head 


\begin{abstract}
Photosynthetic thermal tolerance and recovery to short duration temperature stress in desert and montane plants: A comparative study David William Gallagher
\end{abstract}

- Climate change models predict an increase in frequency and amplitude of extreme weather events, including heat waves. To better predict how the composition and distribution of plant assemblages might respond to these changes in temperature, it is important to understand how species currently respond to these extremes.

Photosynthetic thermal tolerance $\left(T_{25}\right)$ and photosynthetic recovery $\left(R T_{25}\right)$ were quantified in 27 species. We also studied the relationships between $T_{25}, R T_{25}$ and leaf mass per area (LMA). Leaf temperature was also monitored in the field.

- Leaves used in this study were collected from two distinct environments representing desert and montane plant assemblages. $T_{25}$ and $R T_{25}$ were measured using a chlorophyll fluorescence protocol incorporating sub-saturating light and short duration heat stress.

- Mean $T_{25}$ and LMA were significantly different between environments. Mean $R T_{25}$ was not significantly different between environments. There was a positive relationship between $T_{25}$ and LMA in both environments.

- The ability to recover from heat stress does not differ between two biomes that experience vastly different mean maximum temperatures during the summer months. LMA is a predictive leaf trait for thermal tolerance. 


\section{ACKNOWLEDGMENTS}

The author gratefully acknowledges Boyd Deep Canyon Desert Research Center for site access, infrastructure, herbarium, and a laboratory as well as its director, Dr. Allan Muth. We further thank Kim Briones and Travis Parker for assistance in the field and Mark Fisher for technical assistance. Also, we thank Buford Crites and Friends of the Desert Mountains for access to the Santa Rosa Mountain cabin. David W. Gallagher was supported by a Mayhew Graduate Research Award from the Boyd Deep Canyon Desert Research Center. 


\section{TABLE OF CONTENTS}

\section{Page}

LIST OF TABLES viii

LIST OF FIGURES $\quad$ ix

\section{CHAPTER}

I. INTRODUCTION 1

II. MATERIALS AND METHODS 4

Study Areas and Plant Species $\quad 4$

Plant Species Sampling $\quad 4$

Experimental Heat Stress $\quad 5$

Calculation of $T_{25}$ and $R T_{25}$

$\begin{array}{ll}\text { Leaf Temperature } & 8\end{array}$

$\begin{array}{ll}\text { LMA } & 8\end{array}$

Statistical Analysis $\quad 9$

$\begin{array}{ll}\text { III. RESULTS } & 10\end{array}$

Photosynthetic Thermal Tolerance and recovery $\left(T_{25}\right.$ and $\left.R T_{25}\right) \quad 10$

$\begin{array}{ll}\text { LMA } & 11\end{array}$

$\begin{array}{ll}\text { Leaf Temperature } & 11\end{array}$ 
$\begin{array}{ll}\text { IV. DISCUSSION } & 12\end{array}$

$\begin{array}{ll}\text { Photosynthetic recovery }\left(R T_{25}\right) & 12\end{array}$

$T_{25}$, LMA and evolutionary history $\quad 14$

Photosynthetic thermal tolerance $\left(T_{25}\right)$, leaf temperature, and $\begin{array}{ll}\text { heat waves } & 16\end{array}$

$\begin{array}{ll}\text { V. TABLES AND FIGURES } & 19\end{array}$

VI. REFERENCES 26 


\section{LIST OF TABLES}

Table Page

1. Chlorophyll fluorescence parameters used in the calculation of

photosynthetic thermal tolerance and recovery

19

2. Measured leaf properties for 27 desert (D) and montane (M) species 


\section{LIST OF FIGURES}

Figure $\quad$ Page

1. Typical relationships for the temperature dependent changes

in $\triangle F / F_{M}{ }^{\prime}$ and $\triangle F / F_{M}{ }^{\prime} E R$

2. Phylogeny of 27 desert and montane species with photosynthetic thermal tolerance thresholds $\left(T_{25}\right)$ and leaf mass areas (LMA)

3. Mean \% recovery of PSII at $T_{25}\left(R T_{25}\right)$ in 27 desert and montane species

4. The relationships between $T_{25}, R T_{25}$, LMA, and environment for 16 desert and 11 montane species

5. Leaf temperature profiles for six species 


\section{Introduction}

The earth's climate has warmed by $0.6^{\circ} \mathrm{C}$ in the last century and is projected to increase an additional 1.8 to $3.6^{\circ} \mathrm{C}$ in the $21^{\text {st }}$ century. In North America, the mean surface temperature is projected to increase 0.5 to $3^{\circ} \mathrm{C}$ by 2050 . An increase in the frequency and amplitude of extreme events, such as heat waves and extended drought periods, are also predicted (Jones et al., 2001; IPCC, 2007). The rate of climate change potentially could change the distribution and diversity of plant species, resulting in fundamental shifts in the composition of plant communities at the biome level. Changes in distribution could result from the migration of plant species to higher elevations and latitudes or local extinction (Jump \& Peñuelas, 2005; Loarie et al., 2008).

The ability of plant species to persist at their current locations will depend on the specific physiological thresholds and responses of plant species as well as the rate and type of climate change (Walther, 2003). In the context of increasing temperatures, one such threshold is the thermal tolerance threshold of the photosynthetic system. To better predict how the composition and distribution of plant assemblages might shift given the current projections in climate change, it is important to understand how plant species currently respond to temperature stress. These responses include both photosynthetic thermal tolerance and the ability to recover from temperature stress.

Studies of photosynthetic thermal tolerance and photosynthetic recovery have previously been conducted. These studies have been confined to single biomes (Seemann et al., 1979; Downton et al., 1984; Curtis et al., in review), agriculturally important species (Harding et al., 1990; Derocher et al., 1991), or have only investigated a small number of species (Méthy et al., 1997; Heinrich Krause et al., 2010). One study involved a cross-biome comparison (Knight \& Ackerly, 2003), but none have investigated biomes characterized by elevational differences (e.g. montane vs. desert). Currently, there is evidence that climate change is driving the migration of plant species to higher elevations and latitudes (Walther et al., 2002; Parmesan \& Yohe, 2003; Walther, 2003). A crossspecies comparison from desert and montane biomes allows for the investigation of the 
magnitude of the difference in photosynthetic thermal tolerance and photosynthetic recovery between desert and montane plant species. Such a comparison could elucidate the relationship between photosynthetic thermal tolerance and leaf temperatures in the field. For example, desert plant species may be at greater risk from climate change because they currently experience daytime temperatures that are at or near the upper threshold of what many biochemical processes can tolerate.

The use of chlorophyll fluorescence is widely used to evaluate the thermal stability of the photosynthetic pathway (Seemann et al., 1984; Knight \& Ackerly, 2002, 2003). Photosystem II (PSII) is recognized as one of the most thermally sensitive components of the photosynthetic pathway in green leaves (Weiss \& Berry, 1988; Havaux, 1993). When leaf temperature increases, PSII becomes less stable and fluorescence increases. Fluorescence is produced during the rapid decay of excited electrons by chlorophyll $a$ antennae of PSII (Schreiber \& Armond, 1978; Bilger et al., 1984; Weiss \& Berry, 1988; Yamane et al., 2000). Fluorescence methods commonly employed to evaluate thermal damage of leaves measure the maximum efficiency at which light absorbed by PSII is used for reduction of plastoquinone, expressed as $F_{V} / F_{M} . F_{V} / F_{M}$ is an established and reliable parameter to quantify the functionality of the photosynthetic pathway on darkacclimated leaves (Baker, 2008). However, it is known that light during heat stress has protective effects in temperature stressed plants (Havaux et al., 1991; Marutani et al., 2012; Buchner et al., 2013). Moreover, since temperature stress is more likely to occur during daylight hours, photosynthetic thermal tolerance studies that expose leaves to actinic light or natural solar radiation are more ecologically relevant than studies on only dark-acclimated leaves (Curtis et al., in review). For leaves exposed to a particular level of photosynthetic photon flux density (PPFD), the estimate of the maximum efficiency at which light absorbed by PSII is used for reduction of plastoquinone is expressed as $\Delta F / F_{M}{ }^{\prime}$ or photosynthetic efficiency. The extent to which photosynthetic efficiency recovers following an episode of temperature stress could be an important parameter in understanding photosynthetic thermal tolerance in plants.

Another important parameter in photosynthetic thermal tolerance studies is the duration of the heat stress treatments and this has varied considerably among studies 
(from hours to days). Depending on season and time of day, high ambient temperatures can persist for many hours but leaf temperature can remain cool in the presence of convective air currents (Roden \& Pearcy, 1993). However, leaf temperatures can rise rapidly to critical levels within seconds or minutes with transient lulls in wind speed or sun flecks in a canopy. Leaf traits such as leaf size, leaf orientation, and reflectance play important roles in thermal management in desert plants (Ehleringer \& Mooney, 1978; Vogel, 2009). Also, leaves with greater LMA have more thermal mass and therefore a longer thermal time constant (how long it takes for the leaf to respond to a change in temperature), which can buffer leaves against reaching damagingly high temperatures when the thermal environment changes rapidly for a short period (Leigh et al., 2012). Photosynthetic thermal tolerance is not well studied in the context of short episodes of heat stress, which might be more ecologically relevant.

In this study, we asked (1) do desert plants have higher temperature thresholds for photosynthetic thermal tolerance and photosynthetic recovery than plants in a nearby montane environment, (2) do leaf temperatures approach or exceed these tolerances in the field, (3) is there a relationship between LMA and photosynthetic thermal tolerance $\left(T_{25}\right)$ and recovery $\left(R T_{25}\right)$ from short durations of heat stress, and (4) has there been correlated evolution of $T_{25}, R T_{25}$, and LMA. Our technique involved measuring the temperature dependent decrease of $\Delta F / F_{M}{ }^{\prime}$ on leaves exposed to a short period of temperature stress under sub-saturating actinic light. Both Sonoran Desert species and nearby montane species were sampled during the summer months. Leaf temperatures were measured for selected species from both environments. Leaf-mass per area was measured for all species studied. 


\section{Materials and Methods}

Study Areas and Plant Species

The leaves from plants used in the study were collected from two distinct environments representing desert and montane plant assemblages. Desert species were collected from two areas within the Colorado subdivision of the Sonoran Desert: (1) The Philip L. Boyd Deep Canyon Desert Research Center (Boyd Deep Canyon), located near Palm Desert, CA at an elevation of $290 \mathrm{~m}$ and (2) at several non-irrigated ruderal sites located in the northern region of the Coachella Valley between the elevations of $-4 \mathrm{~m}$ and $210 \mathrm{~m}$. Montane species were collected from Santa Rosa Mountain, located in Southern California at an elevation of $2347 \mathrm{~m}$. Boyd Deep Canyon has a mean annual rainfall of $c$. $150 \mathrm{~mm}$ and a mean maximum summer (June-August) temperature of $c .38 .7^{\circ} \mathrm{C}$, with maximum temperatures reaching $>42^{\circ} \mathrm{C}$ in the summer. Coachella Valley has a mean annual rainfall of $c .84 \mathrm{~mm}$ and a mean maximum summer (June-August) temperature of c. $40.5^{\circ} \mathrm{C}$, with maximum temperatures reaching $>45^{\circ} \mathrm{C}$ in summer. Santa Rosa Mountain has a mean annual rainfall of $c .635 \mathrm{~mm}$, mean annual snowfall of $c .965 \mathrm{~mm}$, and a mean maximum summer (June-August) temperature of $c .28 .3^{\circ} \mathrm{C}$, with maximum temperatures reaching $>32^{\circ} \mathrm{C}$ in summer. Species were selected based on the presence of leaves and included a variety of growth forms and leaf morphology. Twenty-seven native perennial herb, shrub, and tree species were sampled across thirteen families. To reduce seasonal bias, data collection took place between June and July in 2013 for the Boyd Deep Canyon and Coachella Valley sites (16 desert species) and between July and August 2013 for Santa Rosa Mountain (11 montane species). Climate data was retrieved from the Western Regional Climate Center (http://www.wrcc.dri.edu).

Plant Species Sampling

For each species, stems were collected from a minimum of five different individuals for each replicate. Stems were collected before 08:30 hours to prevent 
photoinhibition and placed in a black plastic bag with a moistened sponge. Fully expanded leaves were picked from the stems within an hour of collection (with petioles intact if present), placed in a plastic bin lined with a moist paper towel and then tossed to randomly distribute the leaves. The leaves were covered with a moist paper towel and the bin covered with a dark-colored cloth and kept at room temperature $\left(25\right.$ to $27^{\circ} \mathrm{C}$ for plants sampled from Boyd Deep Canyon and Coachella Valley sites; 24 to $26^{\circ} \mathrm{C}$ for plants sampled from Santa Rosa Mountain) until the leaves were selected for the temperature treatments ( $<7$ hours). For each species a minimum of five leaves were randomly selected from the plastic bin for each temperature treatment and placed in a polyethylene Ziploc ${ }^{\circledR}$ bag on a moistened paper napkin. Air pockets were removed prior to sealing the bags. The sample bags were placed in the dark for a minimum of 30 minutes prior to the temperature treatments (dark acclimation).

\section{Experimental Heat Stress}

Our method was based on the methodology of Curtis et al. (in review) with some variation (our light level was slightly higher and our fluorescence measurement intervals were less frequent). Temperature treatments ranged in $2^{\circ} \mathrm{C}$ increments from 42 to $52^{\circ} \mathrm{C}$ for desert species and 38 to $50^{\circ} \mathrm{C}$ for montane species and a control treatment of $28^{\circ} \mathrm{C}$ for both desert and montane species. The control temperature and temperature treatments consisted of temperature-controlled water baths (17.9 liter polyethylene cooler, Model $\underline{3000000433}$, The Coleman Company). For each water bath, water temperature was maintained at the target temperature $\left( \pm 0.5^{\circ} \mathrm{C}\right)$ for the duration of the experiment by a digital thermo-controller (Model 5C6-353, Oven Industries, Inc.) attached to a thermistor temperature probe (Model TS82-154, Oven Industries, Inc.) and a 500-watt titanium submersible heating element (Model TSH-500-SC, JEHM Co., Inc.). Standard aquarium pumps (Model 2802RE1, PETCO Animal Supplies, Inc., Model A-585, Askoll Holding S.r.1., Model PH-601, Meiko Pet Corporation) were used to circulate water in the water bath to eliminate temperature stratification. A single hand-held thermocouple thermometer (Model HH509R, Omega Engineering, Inc.) was used to verify the 
temperature for each temperature treatment. A pilot study demonstrated that leaves (three species tested) on a moist paper towel equilibrated to the temperature of the water bath within a minute after immersion (measured using the above thermocouple thermometer). The control treatment $\left(28^{\circ} \mathrm{C}\right)$ provided a basis for distinguishing any decline in photosynthetic performance associated with detachment of the leaf from the plant, since $28^{\circ} \mathrm{C}$ was not thermally stressful to any of the plant species tested. It also provided a baseline response from which any deviation in $\Delta F / F_{M}{ }^{\prime}$ due to experimental heat stress could be calculated.

For the temperature and control treatments, leaves were exposed to sub-saturating light (a PPFD of 670 to $820 \mu \mathrm{mol} \mathrm{m} \mathrm{m}^{-2}$ ). The light source was from a 12 watt LED lamp (59\% red: $660 \mathrm{~nm}$; 25\% blue: $420 \mathrm{~nm}$; 16\% white) (Model 901430, Agro LED, Sunlight Supply, Inc.) suspended above each water bath.

Each replicated run occurred over two days. A control treatment was included for each replicate. On day one, the sealed sample bags for the control temperature and each temperature treatment (all containing leaves after a minimum 30 minute period of darkacclimation) were placed in a given temperature-controlled bath for 15 minutes. Immediately after removal from the bath ( $<5$ minutes) the ratio of variable to maximal fluorescence $\left(\Delta F / F_{M}{ }^{\prime}\right.$ or photosynthetic efficiency) was determined following actinic light pulses (12000 $\left.\mu \mathrm{mol} \mathrm{m}^{-2} \mathrm{~s}^{-1}, 0.7 \mathrm{~s}\right)$ using a chlorophyll fluorometer (Model FMS2, Hansatech Instruments Limited). The sample bags containing the leaves were then placed in the dark for an extended recovery period (18 to 24 hours). After the recovery period (day two), the sample bags (for both control and temperature treatments) were then placed back in the control bath $\left(28^{\circ} \mathrm{C}\right)$ for 15 minutes (under sub-saturating light), after which $\Delta F / F_{M}{ }^{\prime}$ was immediately measured for each leaf. For each species, the temperature of the successive treatments was increased until a temperature was reached where the average $\Delta F / F_{M}{ }^{\prime}$ value dropped below the calculated $T_{25} \Delta F / F_{M}{ }^{\prime}$ (see below and Table 1 for definitions). Once $T_{25}$ was determined for a species, the order of temperature treatments, including the control, was randomized in subsequent replicates. A minimum of three replicated runs were completed for each species during the study period (Table 2). 
For $94 \%$ of all the replicated runs (100 out of 107), two separate species were placed in the same sample bag.

Calculation of $T_{25}$ and $R T_{25}$

Photosynthetic thermal tolerance $\left(T_{25}\right)$ was calculated from the linear interpolation between the two temperature treatments from day one that bracketed the calculated $25 \%$ decline in $\Delta F / F_{M}{ }^{\prime}$ (Table 2, Fig. 1). Photosynthetic recovery $\left(R T_{25}\right)$ was calculated from the linear interpolation of the average $\triangle F / F_{M}{ }^{\prime} E R$ values from the two temperature treatments used for the $T_{25}$ calculation after an extended recovery period (Table 2 and Fig. 1):

$R T_{25}=\left(\left(\left(T_{25} \Delta F / F_{M}{ }^{\prime} E R-T_{25} \Delta F / F_{M}\right) / T_{25} \Delta F / F_{M}\right)+1\right) \times 100$

Where, $T_{25} \Delta F / F_{M}{ }^{\prime} E R$ is the photosynthetic efficiency of PSII measured the day following heat stress at $T_{25}$ (extended recovery). $T_{25} \Delta F / F_{M}{ }^{\prime}$ is the calculated estimate of the photosynthetic efficiency of PSII after a $25 \%$ reduction in $\Delta F / F_{M}{ }^{\prime}$ at $28^{\circ} \mathrm{C}$ (using day one measurements). For eq. 1 , full recovery of $\Delta F / F_{M}{ }^{\prime}$ at $T_{25}$ would be $100 \%$ (no change in $\left.\Delta F / F_{M}{ }^{\prime}\right)$ and percentages less than $100 \%$ indicate a reduction relative to $T_{25} \Delta F / F_{M}{ }^{\prime}$ and percentages greater than $100 \%$ indicate a gain relative to $T_{25} \Delta F / F_{M^{\prime}}$. See Table 1 for a complete list of the chlorophyll fluorescence parameters used in the calculation of $T_{25}$ and $R T_{25}$. In previous ecological studies, $T_{50}$ has been used to measure photosynthetic thermal tolerance (Knight \& Ackerly, 2003; Curtis et al., in review). $T_{50}$ is measured as the temperature-dependent decline in $F_{V} / F_{M}$, indicating the temperature at which photosynthetic efficiency drops by $50 \%$ after heat stress. In our study, $T_{25}$ was chosen as the metric to measure photosynthetic thermal tolerance because a pilot study showed photosynthetic recovery $\left(R T_{25}\right)$ was considerably less or non-existent at $T_{50}$ than at $T_{25}$. Since a goal of this study was to explore the thresholds for both photosynthetic tolerance and recovery, the $T_{25}$ threshold was chosen because $c .85 \%$ of species had $R T_{25}$ values $>80 \%$. 
Leaf Temperature

Leaf temperatures in the field were recorded using Type E thermocouple sensors (Model SMP series with Model TT-E series 30AWG Type E thermocouple wire, Omega Engineering, Inc.) attached directly to the abaxial side of individual leaves with a minimum amount of breathable first aid tape (Model 10269900, Johnson \& Johnson Secure Comfort First Aid Medical Tape; Model 34-8707-2607-1, 3M Transpore Surgical Tape). The thermocouples were randomly arranged on 5 to 12 leaves for each species, on all sides of the plant. For each species, thermocouples were placed at various heights within the canopy to capture leaf temperature differences as a result of variations in the distance from ground. Leaf temperature data were monitored over a 12 hour period (at one minute intervals) on one individual from six species during the study period on clear or partly cloudy, non-rainy days (Model CR10X data logger and a Model AM25T multiplexer, Campbell Scientific, Inc.). The species (number of leaves monitored, distances from ground) were as follows: Larrea tridentata $(8,28$ to $112 \mathrm{~cm})$, Fouquieria splendens (12, 13 to $133 \mathrm{~cm})$, Chamaesyce albomarginata (9, 0.5 to $5.5 \mathrm{~cm})$, Encelia Farinosa (5, 30 to $56 \mathrm{~cm})$, Quercus chrysolepis $(11,81$ to $267 \mathrm{~cm})$, and Lupinus excubitus $(6,4$ to $7 \mathrm{~cm})$. The variations in distances reflect the different growth habits among the species.

LMA

Leaf mass area (LMA), defined as dry mass per unit area $\left(\mathrm{g} \mathrm{m}^{-2}\right)$ was determined for all 27 species between June and August 2013. The leaves used for LMA determination were from the control treatment $\left(28^{\circ} \mathrm{C}\right)$ samples (See Table 2 for the number of leaves used for each species). Based on the size of the leaf, a circular metal (copper or aluminum) punch, ranging in diameter from 2.35 to $7.85 \mathrm{~mm}$ was used to punch a sample from the leaf. For Senegalia greggi, Prosopis glandulosa, and Ericameria nauseosa, length $(L)$ and width $(W)$ were determined to the nearest $0.01 \mathrm{~mm}$ 
and leaf area was approximated with the formula for the area of an ellipse $(A=\pi \times 1 / 2 L \times$ $1 / 2 W$ ). The samples were dried in a drying oven overnight ( 16 to 24 hours) at $46^{\circ} \mathrm{C}$. The dried samples were weighed to the nearest mg (Model VP214CN, Ohaus Corporation).

Statistical Analysis

Data were analyzed using the software JMP (version 10). Paired $t$-tests were used to analyze the difference between $\Delta F / F_{M}{ }^{\prime}$ and $\Delta F / F_{M}{ }^{\prime} E R$ for the control treatment. Student's $t$-tests were used to analyze differences in $T_{25}, R T_{25}$, LMA and environment. One-way ANOVA (general linear model) tests were used to analyze the differences in $T_{25}$ and $R T_{25}$ for all species. Multiple regression analysis (general linear model) was performed to assess the relationships among $T_{25}, R T_{25}$, LMA and environment. A phylogenetic tree was created with Phylomatic (version 3) and Interactive Tree Of Life (iTOL), both online phylogenetic tools (http://phylodiversity.net/phylomatic/ and http://itol.embl.de/, respectively). The phylogenetic independent contrast analyses were completed in $\mathrm{R}$ (version 3.0.1) using the package 'ape' (Paradis et al., 2004). 


\section{Results}

Photosynthetic Thermal Tolerance and recovery $\left(T_{25}\right.$ and $\left.R T_{25}\right)$

For leaves at the control temperature $\left(28^{\circ} \mathrm{C}\right)$, there was a significant difference between mean photosynthetic efficiency of PSII $\left(\Delta F / F_{M}{ }^{\prime}=0.737\right)$ and mean recovery of photosynthetic efficiency of PSII $\left(\triangle F / F_{M}{ }^{\prime} E R=0.695\right)$ across all species $(t=5.85, d f=25$, $P<0.05)$. After adjusting for species within environment, the difference in photosynthetic efficiency was significant between mean $\Delta F / F_{M}{ }^{\prime}($ desert $=0.727$, montane $=0.751)$ and mean $\Delta F / F_{M}^{\prime} E R($ desert $=0.682$, montane $=0.713 ; t=4.61, d f=14, P<$ $0.05 ; t=3.45, d f=9, P<0.05$, respectively). The average decline was $5.7 \%$ across all species, indicating that our detached leaf extended recovery protocol was a viable experimental strategy.

$T_{25}$ ranged from 45.5 to $51.3^{\circ} \mathrm{C}$ in desert species and 40.5 to $46.5^{\circ} \mathrm{C}$ in montane species (Fig. 2 and Table 2). There was a significant difference for mean $T_{25}$ between desert $\left(48.3^{\circ} \mathrm{C}\right)$ and montane $\left(44.6^{\circ} \mathrm{C}\right)$ environments $(t=5.52, d f=17.7, P<0.05)$. Additionally, there were significant differences in $T_{25}$ among species $\left(F_{26,106}=8.89, P<\right.$ $0.05)$.

Percent recovery $\left(R T_{25}\right)$ ranged from 57.9 to $120.0 \%$ in the 16 desert species and 59.4 and $110.9 \%$ in the 11 montane species (Fig. 3 and Table 2). There was not a significant difference for mean $R T_{25}$ between the desert (98.0\%) and montane $(88.2 \%)$ environments $(t=1.54, d f=20.3, P>0.05)$. However, there were significant differences in $R T_{25}$ among species $\left(F_{26,106}=3.14, P<0.05\right)$.

There was a negative relationship between $T_{25}$ and $R T_{25}$ accounting for native environment $\left(F_{2,24}=4.80, P<0.05\right.$; Fig. $\left.4 \mathrm{~b}\right)$. A phylogenetic independent contrast analysis did not find a relationship between $T_{25}$ and $R T_{25}$, after accounting for environment $\left(P I C_{r 2,23}=2.71, P>0.05\right)$. 
LMA

Average LMA was significantly different between desert $\left(250 \mathrm{~g} \mathrm{~m}^{-2}\right)$ and montane $\left(140 \mathrm{~g} \mathrm{~m}^{-2}\right)$ species $(t=3.32, d f=21.2, P<0.05)$. LMA ranged from a low of $50 \mathrm{~g} \mathrm{~m}^{-2}$ to a high of $440 \mathrm{~g} \mathrm{~m}^{-2}$ across all 27 species (Fig. 4 and Table 2). There was a positive relationship between $T_{25}$ and LMA after accounting for native environment $\left(F_{2,24}=17.5\right.$, $P<0.05$; Fig. 4a). There was not a relationship between $R T_{25}$ and LMA after accounting for environment $\left(F_{2,24}=1.80, P>0.05\right.$; Fig. $\left.4 \mathrm{c}\right)$. A phylogenetic independent contrast analysis found a positive relationship between $T_{25}$ and LMA $\left(P I C_{r}=2.88, d f=25, P<\right.$ $0.05)$, but not for $R T_{25}$ and LMA $\left(P I C_{r}=1.98, d f=25, P>0.05\right)$. The best models did not include environment as a parameter.

\section{Leaf Temperature}

In Chamaesyce albomarginata, Encelia farinosa and Fouquieria splendens (all desert species) leaf temperatures exceeded $T_{25}$ in the field (Fig. 5). The temperature excursions above $T_{25}$ lasted from minutes ( $F$. splendens) to hours ( $C$. albomarginata and E. farinosa) with average high ambient air temperatures between 37.8 and $39^{\circ} \mathrm{C}$ during the hottest part of the day (as recorded by a nearby weather station at $1.9 \mathrm{~m}$ from the ground). In Larrea tridentata (desert species), Lupinus excubitus (montane species), and Quercus chrysolepis (montane species) leaf temperatures did not exceed $T_{25}$ (Fig. 5). For the montane species, average high ambient air temperatures were between 28.2 and $29.1^{\circ} \mathrm{C}$ during the hottest part of the day. Maximum leaf temperatures ranged between 8 and $20^{\circ} \mathrm{C}$ above the mean high ambient air temperature for desert plants and between 11 and $13^{\circ} \mathrm{C}$ above the mean for montane plants. 


\section{Discussion}

Photosynthetic recovery $\left(R T_{25}\right)$

Recovery from heat stress $\left(R T_{25}\right)$ showed significant variation among species within each environment (Table 2). For example, there was a difference of c. $60 \%$ between the desert species Isocoma acradenia (-57.9\%) and Chilopsis linearis (120\%). However, our measure of recovery did not demonstrate a significant difference in $R T_{25}$ between desert and montane plants. Interestingly, there was a negative relationship between $T_{25}$ and $R T_{25}$ in both environments (Fig. 4b). Plants with greater thermal tolerance thresholds $\left(T_{25}\right)$ recovered less of their pre-stress photosynthetic efficiency. For example, the desert perennial, Isocoma acradenia recovered c. 58\% of its photosynthetic efficiency but had a $T_{25}$ value of $47.4^{\circ} \mathrm{C}$. Likewise, four montane plants, the small herb Astragalus leucolobus, the shrub Ribes cereum, the small herb Euphorbia lurida, and the shrub Symphoricarpos rotundifolius all had the lowest $T_{25}$ values of all species tested ( 40.5 to $43.7^{\circ} \mathrm{C}$ ), but all had the highest $R T_{25}$ values ( $100 \%$ or more). In other words, at low temperature treatments species recovered to high levels of photosystem function after heat stress and the reverse was true for species that had higher $T_{25}$ values (stressed at higher temperatures). Additionally, phylogenetic independent contrasts did not support correlated evolution between thermal tolerance and recovery, suggesting that an intrinsic ability to recover from heat stress did not co-evolve with thermal tolerance thresholds, regardless of native environment.

Not surprisingly, our findings also demonstrated that all species tested had a range of temperatures at which they exhibited recovery after heat stress (represented by the area between the extended recovery and temperature stress curves in Fig. 1) along with an upper temperature beyond which recovery did not take place (represented by the convergence of the extended recovery and temperature stress curves at high temperatures in Fig. 1). The temperatures at which recovery did not take place usually were within $2{ }^{\circ} \mathrm{C}$ 
of species' corresponding $T_{25}$ thresholds (data not shown). Presumably these higher temperatures resulted in permanent damage to the photosynthetic machinery or our recovery period was not long enough to allow full recovery to be measured.

The observed variations in $R T_{25}$ could be a result of differences in the intensity of thermal stress (temperature treatments) applied. For example, species with high $T_{25}$ values required higher temperatures to induce declines in photosynthetic efficiency by $25 \%$. The low temperature treatments associated with low $T_{25}$ values may have only down-regulated the PSII reaction centers, which would recover quickly (minutes to hours) after thermal stress (Krause, 1994). Species with greater $T_{25}$ thresholds may have experienced moderate heat stress, resulting in short to long-term reversible damage to PSII, such as disruption of the PSII water-splitting reaction and degradation of the D1 protein (Aro et al., 1994). Therefore, longer recovery times ( $>24$ hours) could have resulted in greater gains of photosynthetic efficiency. However, some species such as Isocoma acradenia $\left(T_{25}=47.4^{\circ} \mathrm{C}, R T_{25}=57.9 \%\right)$ may have experienced extreme heat stress, which resulted in irreparable damage to the photosynthetic pathway (e.g. separation of the PSII reaction center from the light harvesting complex; Yamane et al., 1997, 1998). Additionally, different stages of leaf senescence could be a significant variable in recovery from thermal stress, particularly the de novo synthesis of the D1 protein (Nath et al., 2013). Although, none of the leaves collected for this study showed signs of advanced senescence.

The most interesting aspect of $R T_{25}$ is that desert and montane plants have similar intrinsic abilities to recover from experimental heat stress regardless of the typical temperatures that cause stress in each environment. From an ecological perspective, physiological recovery from heat stress would be an important aspect for species persistence, regardless of the temperature that induced the heat stress. It would follow that for a montane species, persistence would mean having the ability to recover from heat stress induced at lower temperatures versus a desert plant, which would have to possess the ability to recover from heat stress induced at higher temperatures. Our results indicate that desert and montane plants both have a marginal buffer for recovering from 
the damaging effects of heat stress, but this buffer is altered to reflect heat stress actually experienced in the field.

We suggest that $R T_{25}$ is a useful indicator of a species' ability to recover after a species specific heat stress event, since $c .85 \%$ of species had $R T_{25}$ values $>80 \%$.

$T_{25}$, LMA and evolutionary history

Even though it was not unexpected that our results found that desert plants have a higher mean $T_{25}$ threshold than montane plants $\left(48.3^{\circ} \mathrm{C}\right.$ and $44.6^{\circ} \mathrm{C}$, respectively), our results raised an intriguing question: Why do montane plants have such high thermal tolerances if leaf temperatures may never approach or exceed their $T_{25}$ thresholds? The answer to this question may be found in the positive relationship between $T_{25}$ and LMA as well as the evolutionary history of $T_{25}$ and LMA.

Phylogenetic analyses supported correlated evolution between $T_{25}$ and LMA but not between $R T_{25}$ and LMA, suggesting that when a species evolved high LMA leaves, increased thermal tolerance followed but not necessarily greater intrinsic recovery. Desert plants had leaves with greater LMA (c. 1.8 times greater) than montane plants $\left(250 \mathrm{~g} \mathrm{~m}^{-2}\right.$ and $140 \mathrm{~g} \mathrm{~m}^{-2}$, respectively). LMA is correlated with other leaf traits (thicker, narrower, and more reflective) that can confer thermal protection (Curtis et al., 2012) and itself can mitigate the effects of thermal damage during short periods of extreme thermal stress (Leigh et al., 2012). In the current study, the relationship between LMA and $T_{25}$ (Fig. 4a), but not $R T_{25}$ (Fig. 4c), suggests that LMA is a good predictor of thermal tolerance but not the ability for leaves to recover from heat stress.

Correlated evolution between $T_{25}$ and LMA would help explain why closely related species (i.e. species with a common ancestor) could have a similar LMA and $\mathrm{T}_{25}$ threshold, even if these species are found in different environments (e.g. Hyptis emoryi and Salvia pachyphylla; Table 2, Fig. 2). It is known from packrat middens that Hyptis emoryi has been present in the Sonoran desert from the early to middle Holocene (4.4 to 9.9 kyp) and probably arrived from Mexico as the climate shifted from a cooler and wetter environment to one with hotter summers (Van Devender, 1990). Salvia 
pachyphylla belongs to a monophyletic group with the common ancestor probably originating in Mexico as well (Walker et al., 2004). If a common ancestor to both of these species was adapted to a hot arid environment, and if $T_{25}$ and LMA were selectively neutral, then a daughter species that later encountered a cooler montane environment may have retained a similarly high LMA and $T_{25}$ threshold. It is also possible that both of these species are too recently related for substantial phenotypic divergence of $T_{25}$ and LMA. However, LMA and $T_{25}$ could also experience different evolutionary trajectories. Even though there is a positive relationship between $T_{25}$ and LMA, photosynthetic thermal tolerance could remain selectively neutral with LMA subject to divergent evolution. For example, the two related species, Isocoma acradenia and Solidago velutina both have statistically identical $T_{25}$ thresholds but very different LMA values (440 $\mathrm{g} \mathrm{m}^{-2}$ and $140 \mathrm{~g} \mathrm{~m}^{-2}$, respectively; Table 2, Fig. 2).

Another consideration is the plastic acclimation of photosynthetic thermal tolerance and LMA. Acclimation of photosynthesis and/or LMA to local climate conditions may obscure the relationship of LMA and $T_{25}$ for both desert and montane environments. Desert species exhibit a capacity for acclimation up to $c .5^{\circ} \mathrm{C}$ between the spring and summer seasons (Downton et al., 1984). Also, congeneric desert and coastal species have the capacity for significant plastic acclimation in photosynthetic thermal tolerance and LMA when grown in a common environment compared to observed field values (Knight \& Ackerly, 2003). Because we did not use a common environment study, the influence of plastic acclimation of photosynthesis or LMA are not known for the species in our study.

There was a significant difference of $5.8^{\circ} \mathrm{C}$ and $6.0^{\circ} \mathrm{C}$ between the least and most thermally tolerant species in both desert and montane environments, respectively. A similar study of Australian desert species found a range of $c .6^{\circ} \mathrm{C}$ in thermal thresholds ( $T_{50}$; Curtis et al., in review) and a study of California desert plants found a range of $c$. $4^{\circ} \mathrm{C}$ in thermal thresholds ( $T_{50}$; Knight \& Ackerly, 2003). Our findings also demonstrate that within a biome, $T_{25}$ varies from species to species within a similar range of temperatures. By contrast, the difference of only $3.7^{\circ} \mathrm{C}$ in $T_{25}$ between montane and desert species is surprising, given that daytime temperatures in the desert are $c .10^{\circ} \mathrm{C}$ 
higher during the summer. On the other hand, this small difference in $T_{25}$ may be reflective of the overall variation in intrinsic photosynthetic thermal tolerance, i.e. it might be more useful to look at variance in $T_{25}$ as a continuum, regardless of environment.

Given this perspective on $T_{25}$, it is possible that common ancestors to these groups were intrinsically thermal tolerant. Historic climate variability during the evolution of land plants may have favored species with robust photosynthetic thermal tolerance thresholds. Species with a longer evolutionary history associated with their current environment may have undergone a divergence in intrinsic photosynthetic thermal tolerance (e.g. the montane species Astragalus leucolobus, which had the lowest $T_{25}$ threshold and the desert species Atriplex hymenelytra, which had one of the highest $T_{25}$ thresholds, Table 2, Fig. 2).

Photosynthetic thermal tolerance $\left(T_{25}\right)$, leaf temperature, and heat waves

Leaf temperature for three desert species exceeded their $T_{25}$ thresholds for minutes to hours (Fig. 5). For example, field-measured leaf temperatures for Chamaesyce albomarginata exceeded its $T_{25}$ threshold of $47.8^{\circ} \mathrm{C}$ (one leaf out of nine) for several hours (Fig. 5). Also, it is noteworthy that the highest leaf temperatures recorded in our study were for Encelia farinosa at $c .58^{\circ} \mathrm{C}$ (for two leaves out of five), which was well above its $T_{25}$ threshold of $46.4^{\circ} \mathrm{C}$ and most likely above the temperature at which tissue death would occur. Leaf senescence could be responsible for the high leaf temperatures because the two leaves were non-pubescent winter/spring leaves and were probably at the end of their life cycles (Housman et al., 2002). It is unclear what the fate of other leaves that regularly exceeded their $T_{25}$ thresholds would be on a whole plant under field conditions, but our study demonstrated that photosynthetic efficiency rapidly decreases with temperature increases of $<2^{\circ} \mathrm{C}$ and the ability of the photosynthetic machinery to recover decreases rapidly as well. Of the four desert plants with leaf temperature data, only Larrea tridentata leaf temperatures did not exceed its $T_{25}$ threshold of $51.3^{\circ} \mathrm{C}$ (Fig. 5). L. tridentata was also the most thermally tolerant of all plants in the study. 
Interestingly leaf temperature for the two montane plants never exceeded their $T_{25}$ thresholds.

Leaves of plants can reach temperatures as high as $20^{\circ} \mathrm{C}$ above ambient temperature depending on transpiration, leaf morphology, leaf shape, reflectance, wind speed, canopy position, and distance from ground (Roden \& Pearcy, 1993; Leigh et al., 2006; Vogel, 2009). Leaf temperatures in this study ranged from 8 to $15^{\circ} \mathrm{C}$ (desert plants, after removing the two E. farinosa leaves with measured temperatures of $c .58^{\circ} \mathrm{C}$ ) and 11 to $13^{\circ} \mathrm{C}$ (montane plants) above the mean high ambient air temperature (during the hottest part of the day), which only varied by $1.2^{\circ} \mathrm{C}$ for the desert environment and $0.9^{\circ} \mathrm{C}$ for the montane environment (Fig. 5). We extrapolated leaf temperatures for days that were considered an extreme temperature event (heat wave) for both environments. In the desert, a maximum high temperature range of 42.4 to $43^{\circ} \mathrm{C}$ was recorded for a three-hour period in August 2013. Projected leaf temperatures (assuming that leaf temperatures would range from 8 to $15^{\circ} \mathrm{C}$ above ambient temperature) would range from 51 to $58.0^{\circ} \mathrm{C}$, exceeding the $T_{25}$ thresholds of the four desert plants for which we measured leaf temperatures. In the montane environment, a maximum high temperature range of 30.1 to $30.5^{\circ} \mathrm{C}$ (assuming that leaf temperatures would range from 11 to $13^{\circ} \mathrm{C}$ above ambient temperature) was recorded for a two-hour period in August 2013. Projected leaf temperatures would range from 41.5 to $43.5^{\circ} \mathrm{C}$, which would not exceed the $T_{25}$ thresholds of the two montane plants for which we measured leaf temperatures. The leaf temperature data presented here are far from complete (data are from a 12 hour period and only one plant was monitored for each species) and does not include all species sampled, so a more thorough study of leaf temperature is necessary to elucidate the relationship between $T_{25}$ and leaf temperature in the field.

Our findings suggest that $T_{25}$ and $R T_{25}$ are useful metrics for comparing thermal thresholds between species and biomes, since $c .85 \%$ of species exhibited strong recovery at $T_{25}\left(R T_{25}\right.$ values $\left.>80 \%\right)$. Our study also found that the ability to recover from heat stress at a species' $T_{25}$ does not differ between two biomes that experience vastly different mean maximum temperatures during the summer months. Additionally, one of 
the most interesting aspects of our study is that high thermal tolerance does not translate to greater recovery of photosynthetic efficiency after temperature stress. For both biomes, LMA is an important leaf trait for predicting thermal tolerance. For desert species, leaf temperatures exceeded thermal tolerance thresholds but since our recovery metric $\left(R T_{25}\right)$ was only determined at $T_{25}$ thresholds, the potential for thermal damage associated with these high temperature excursions is unknown. For future work, we suggest using our chlorophyll fluorescence methodology to measure photosynthetic recovery on leaves after naturally occurring heat stress in the field. Additional future work should also include a common environment study to quantify the intrinsic plasticity of photosynthetic thermal tolerance. These future directions could provide a more complete understanding of the relationship between leaf temperature, photosynthetic thermal tolerance, and climate. Our results indicate that montane plants may have the capacity to withstand moderate increases in temperature and therefore their current distribution will likely remain unchanged. However, desert plants are already operating at or near their physiological limits of thermal tolerance and therefore may not be able to withstand similar increases in temperature. We suggest that desert plants may be more at risk from climate change than those in milder biomes. 


\section{Tables and Figures}

Table 1. Chlorophyll fluorescence parameters used in the calculation of photosynthetic thermal tolerance and recovery.

\begin{tabular}{|c|c|}
\hline Parameter & Definition \\
\hline$\Delta F / F_{M}{ }^{\prime}$ & $\begin{array}{l}\text { Measured estimate of the photosynthetic efficiency of PSII exposed to a } \\
\text { PPFD of } 670 \text { to } 820 \mu \mathrm{mol} \mathrm{m} \mathrm{s}^{-1} \text { at a given temperature treatment. }\end{array}$ \\
\hline $\begin{array}{l}\Delta F / F_{M}{ }^{\prime} a t \\
28^{\circ} \mathrm{C}\end{array}$ & $\begin{array}{l}\text { Measured estimate of the photosynthetic efficiency of PSII exposed to a } \\
\text { PPFD of } 670 \text { to } 820 \mu \mathrm{mol} \mathrm{m} \mathrm{s}^{-1} \text { at a control temperature of } 28^{\circ} \mathrm{C} \text {. }\end{array}$ \\
\hline$T_{25} \Delta F / F_{M}^{\prime}$ & $\begin{array}{l}\text { Calculated estimate of the photosynthetic efficiency of PSII after a } 25 \% \\
\text { reduction in } \Delta F / F_{M}{ }^{\prime} \text { at } 28^{\circ} \mathrm{C}\left(\Delta F / F_{M}{ }^{\prime} \text { at } 28^{\circ} \mathrm{C} \text { x } 0.75\right) \text {. Used as a } \\
\text { benchmark for determining photosynthetic thermal tolerance after } \\
\text { experimental heat stress. }\end{array}$ \\
\hline$T_{25}$ & $\begin{array}{l}\text { Photosynthetic thermal tolerance }\left({ }^{\circ} \mathrm{C}\right) \text { is the temperature at which } \\
\text { photosynthetic efficiency drops by } 25 \% \text { after heat stress. Calculated from } \\
\text { the linear interpolation of the two temperature treatments with average } \\
\Delta F / F_{M} \text { 'values above and below } T_{25} \Delta F / F_{M} \text { '. }\end{array}$ \\
\hline$\Delta F / F_{M}^{\prime} E R$ & $\begin{array}{l}\text { Measured estimate of the photosynthetic efficiency of PSII exposed to a } \\
\text { PPFD of } 670 \text { to } 820 \mu \mathrm{mol} \mathrm{m} \mathrm{m}^{-2} \mathrm{~s}^{-1} \text { after an extended recovery period of } 18 \\
\text { to } 24 \text { hours at a given temperature treatment. }\end{array}$ \\
\hline$T_{25} \Delta F / F_{M}^{\prime} E R$ & $\begin{array}{l}\text { Estimate of the photosynthetic efficiency of PSII at } T_{25} \text { after an extended } \\
\text { recovery period of } 18 \text { to } 24 \text { hours. Calculated from the linear interpolation } \\
\text { of the average } \triangle F / F_{M}^{\prime} E R \text { values from the two temperature treatments used } \\
\text { for the } T_{25} \text { calculation. }\end{array}$ \\
\hline$R T_{25}$ & $\begin{array}{l}\text { Photosynthetic recovery at } T_{25} \text { expressed as a percentage after an extended } \\
\text { recovery period. Calculated from the formula: }\left(\left(\left(\Delta F / F_{M}{ }_{E R}-T_{25} \Delta F / F_{M}\right) /\right.\right. \\
\left.\left.T_{25} \Delta F / F_{M}\right)+1\right) \text { x } 100 \text {. Full recovery of } \Delta F / F_{M}{ }^{\prime} \text { at } T_{25} \text { would be } 100 \% \text { (no } \\
\left.\text { change in } \Delta F / F_{M}\right) \text { and percentages less than } 100 \% \text { indicate a reduction in } \\
\Delta F / F_{M} \text { and percentages greater than } 100 \% \text { indicate a gain in } \Delta F / F_{M}^{\prime} .\end{array}$ \\
\hline
\end{tabular}


Table 2. Measured leaf properties for 27 desert (D) and montane (M) species.

Photosynthetic thermal tolerance $\left(T_{25}\right)$ is the temperature at which photosynthetic efficiency drops by $25 \%$ after heat stress. $R T_{25}$ is the recovery of photosynthetic efficiency at $T_{25}$ after an extended recovery period (expressed as a percentage). Leaf mass area (LMA) is defined as the dry mass per unit area ( \pm SEM based on (x) replicates).

\begin{tabular}{|c|c|c|c|}
\hline Species & $\boldsymbol{T}_{25}\left({ }^{\circ} \mathrm{C}\right)$ & $\boldsymbol{R T}_{25}(\%)$ & LMA $\left(\mathrm{g} \mathrm{m}^{-2}\right)$ \\
\hline Atriplex canescens (D) & $48.4 \pm 0.6(4)$ & $111.8 \pm 8.5(4)$ & $400 \pm 20(12)$ \\
\hline Atriplex hymenelytra (D) & $50.0 \pm 0.6(3)$ & $106.4 \pm 4.3(3)$ & $390 \pm 10(10)$ \\
\hline Atriplex polycarpa (D) & $48.6 \pm 1.8(3)$ & $107.3 \pm 12.3(3)$ & $390 \pm 30(5)$ \\
\hline Chamaesyce albomarginata (D) & $47.8 \pm 0.2(4)$ & $102.0 \pm 3.7(4)$ & $100 \pm 10(9)$ \\
\hline Chilopsis linearis (D) & $47.0 \pm 0.3(4)$ & $120.0 \pm 2.3(4)$ & $280 \pm 20(18)$ \\
\hline Encelia farinosa (D) & $46.4 \pm 0.2(4)$ & $88.3 \pm 2.4(4)$ & $150 \pm 10(18)$ \\
\hline Fouquieria splendens (D) & $45.5 \pm 0.7(4)$ & $116.1 \pm 2.3(4)$ & $68 \pm 4(7)$ \\
\hline Hyptis emoryi (D) & $48.3 \pm 0.6(5)$ & $108.0 \pm 7.1(5)$ & $240 \pm 20(11)$ \\
\hline Isocoma acradenia (D) & $47.4 \pm 0.4(3)$ & $57.9 \pm 16.5(3)$ & $440 \pm 20(7)$ \\
\hline Larrea tridentata (D) & $51.3 \pm 0.4(3)$ & $82.2 \pm 10.8(3)$ & $200 \pm 10(7)$ \\
\hline Psorothamnus emoryi (D) & $50.1 \pm 0.1(4)$ & $82.9 \pm 11.8(4)$ & $250 \pm 20(10)$ \\
\hline Parkinsonia florida (D) & $48.7 \pm 0.3(4)$ & $99.0 \pm 9.7(4)$ & $100 \pm 20(10)$ \\
\hline Prosopis glandulosa (D) & $47.9 \pm 0.5(4)$ & $100.0 \pm 2.0$ & $160 \pm 10(9)$ \\
\hline Petalonyx thurberi (D) & $47.2 \pm 0.6(3)$ & $102.1 \pm 2.0(3)$ & $260 \pm 10(10)$ \\
\hline Senegalia greggi (D) & $48.9 \pm 1.0(4)$ & $96.7 \pm 10.0$ & $130 \pm 10(10)$ \\
\hline Tiquilia plicata (D) & $48.7 \pm 0.5(4)$ & $88.5 \pm 12.8(4)$ & $390 \pm 40(12)$ \\
\hline Astragalus douglasii (M) & $46.1 \pm 0.7(4)$ & $82.7 \pm 14.8(4)$ & $50 \pm 3(9)$ \\
\hline Astragalus leucolobus (M) & $40.5 \pm 1.2(3)$ & $110.9 \pm 4.0(3)$ & $120 \pm 20(3)$ \\
\hline Euphorbia lurida (M) & $42.9 \pm 1.0(5)$ & $98.1 \pm 11.9(5)$ & $100 \pm 2(8)$ \\
\hline Ericamerica nauseosa $(\mathrm{M})$ & $45.6 \pm 0.3(4)$ & $72.1 \pm 6.1(4)$ & $150 \pm 10(9)$ \\
\hline Lupinus excubitus (M) & $44.9 \pm 1.1(4)$ & $70.8 \pm 13.8(4)$ & $170 \pm 10(11)$ \\
\hline Lupinus hyacinthinus (M) & $45.2 \pm 0.4(4)$ & $59.4 \pm 5.7(4)$ & $150 \pm 10(10)$ \\
\hline Quercus chrysolepis (M) & $46.5 \pm 1.4(5)$ & $89.6 \pm 10.1(5)$ & $220 \pm 10(25)$ \\
\hline Ribes cereum (M) & $42.9 \pm 0.4(4)$ & $112.2 \pm 1.5(4)$ & $100 \pm 4(17)$ \\
\hline Salvia pachyphylla $(\mathrm{M})$ & $46.4 \pm 0.7(5)$ & $89.9 \pm 7.6(5)$ & $210 \pm 10(20)$ \\
\hline Symphoricarpos rotundifolius (M) & $43.7 \pm 1.0(4)$ & $102.8 \pm 9.2(4)$ & $120 \pm 10(14)$ \\
\hline Solidago velutina $(\mathrm{M})$ & $46.0 \pm 0.6(5)$ & $81.9 \pm 8.4(5)$ & $140 \pm 10(20)$ \\
\hline
\end{tabular}




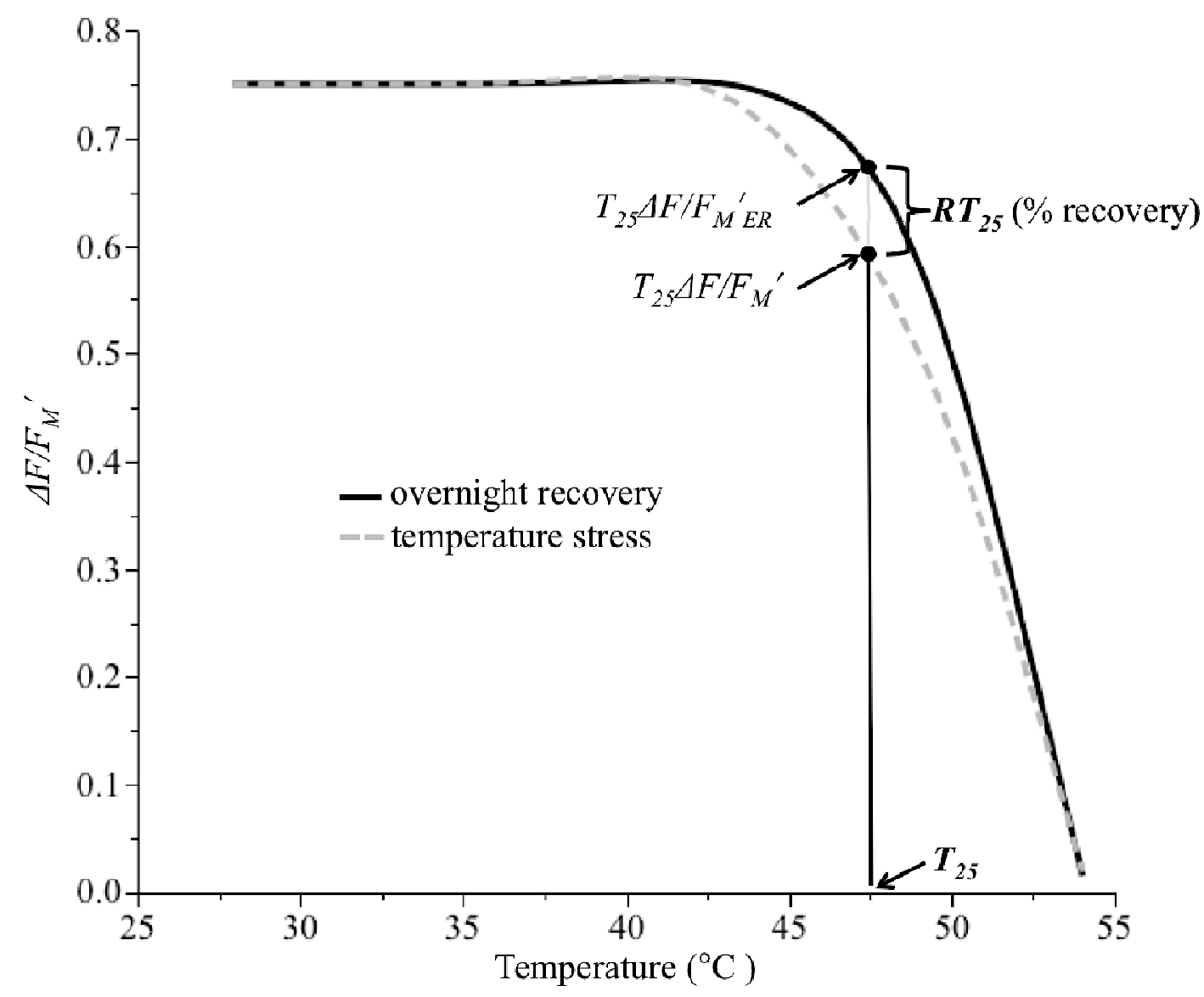

Figure 1. Typical relationships for the temperature dependent changes in $\Delta F / F_{M}{ }^{\prime}$ and $\triangle F / F_{M}{ }^{\prime} E R$. Thermal tolerance $\left(T_{25}\right)$ was calculated from the linear interpolation of the two temperature treatments with average $\Delta F / F_{M}{ }^{\prime}$ values above and below $75 \%$ of the $28^{\circ} \mathrm{C}$ control treatment $\Delta F / F_{M}{ }^{\prime}\left(T_{25} \Delta F / F_{M}{ }^{\prime}\right)$. The photosynthetic efficiency of PSII at $T_{25}$, after an extended recovery period, is $T_{25} \Delta F / F_{M}^{\prime} E R$ and was calculated from the linear interpolation from the average $\triangle F / F_{M}{ }^{\prime} E R$ values from the two temperature treatments used for the $T_{25}$ calculation. Percent recovery at $T_{25}\left(R T_{25}\right)$ was calculated from the formula: $\left(\left(\left(\Delta F / F_{M}^{\prime} E R-T_{25} \Delta F / F_{M}\right) / T_{25} \Delta F / F_{M}\right)+1\right) \times 100$. Both $T_{25}$ and $R T_{25}$ were used for comparison between species and environments. 


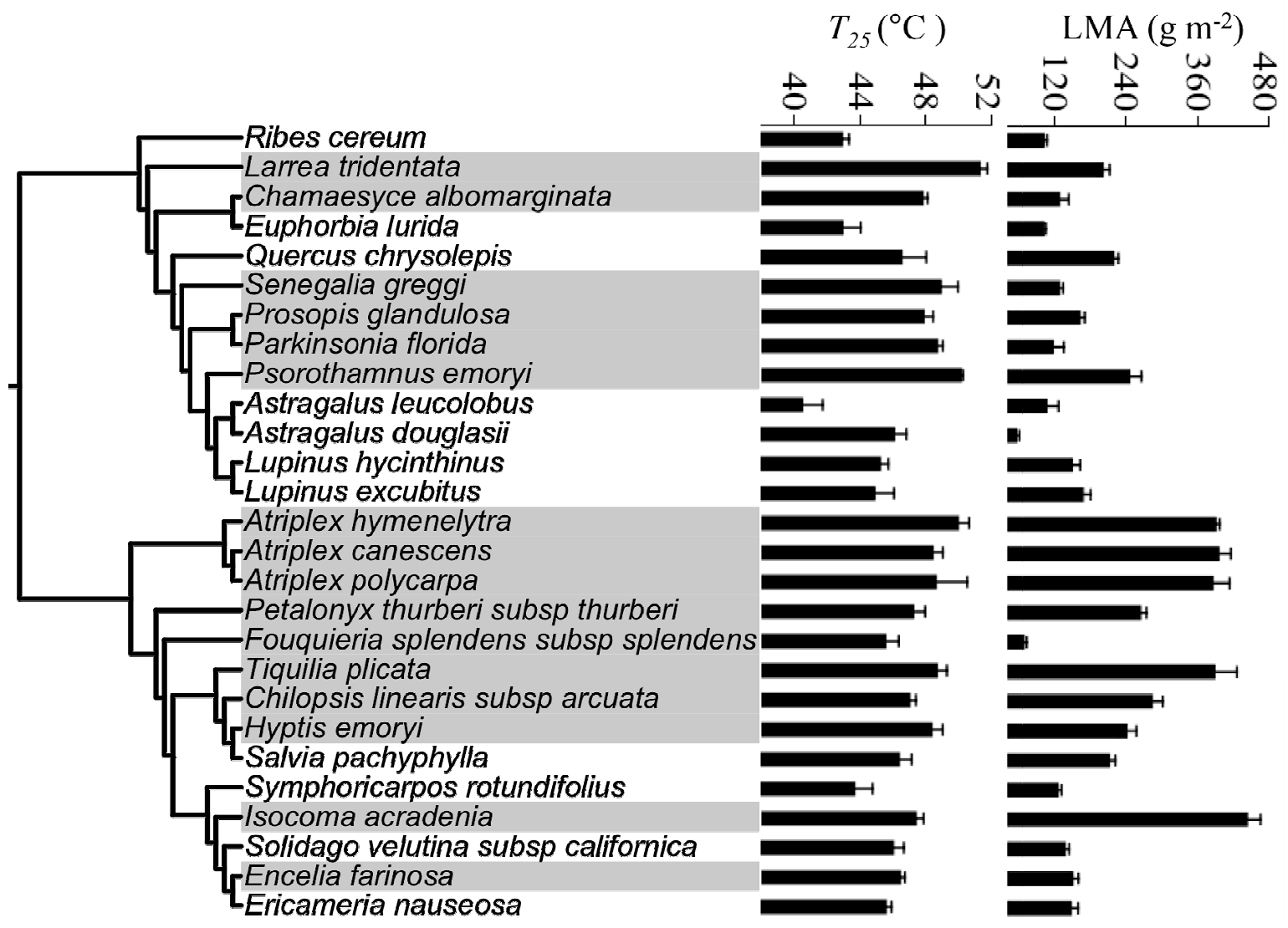

Figure 2. Phylogeny of 27 desert and montane species with photosynthetic thermal tolerance thresholds $\left(T_{25}\right)$ and leaf mass areas (LMA). Thermal tolerance $\left(T_{25}\right)$ is defined as the temperature at which photosynthetic efficiency $\left(\Delta F / F_{M}\right)$ drops by $25 \%$ after heat stress. Leaf mass area is defined as dry mass per unit area. Shaded species are from desert environments. The error bars denote $1 \mathrm{SE}$. 


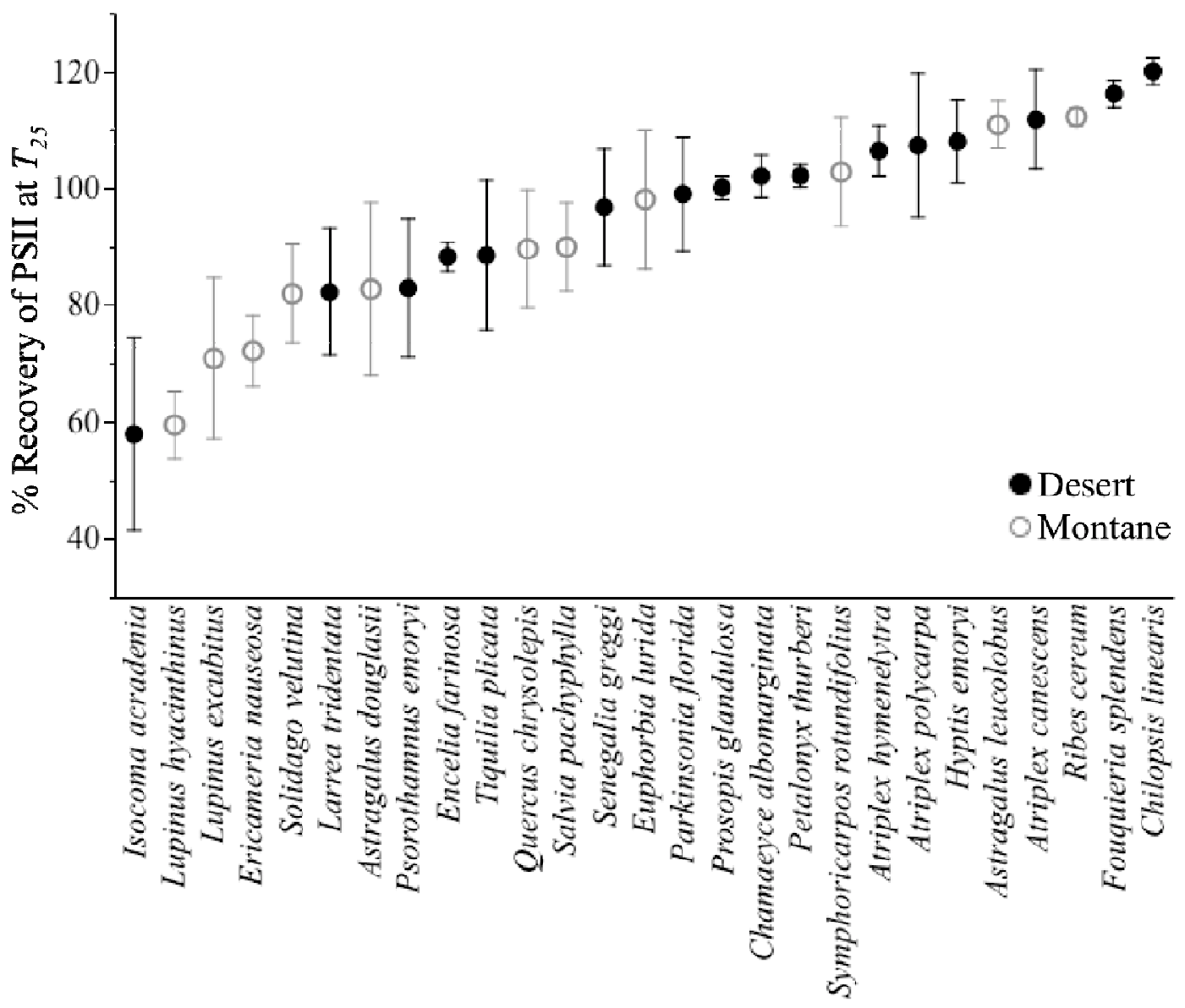

Figure 3. Mean \% recovery of PSII at $T_{25}\left(R T_{25}\right)$ in 27 desert and montane species. $R T_{25}$ was measured after an extended recovery period. Full recovery at $T_{25}$ would be $100 \%$. Percentages less than $100 \%$ indicate a lack of full recovery of PSII efficiency and percentages greater than $100 \%$ indicate a gain in PSII efficiency. The error bars denote 1SE. 
(a)

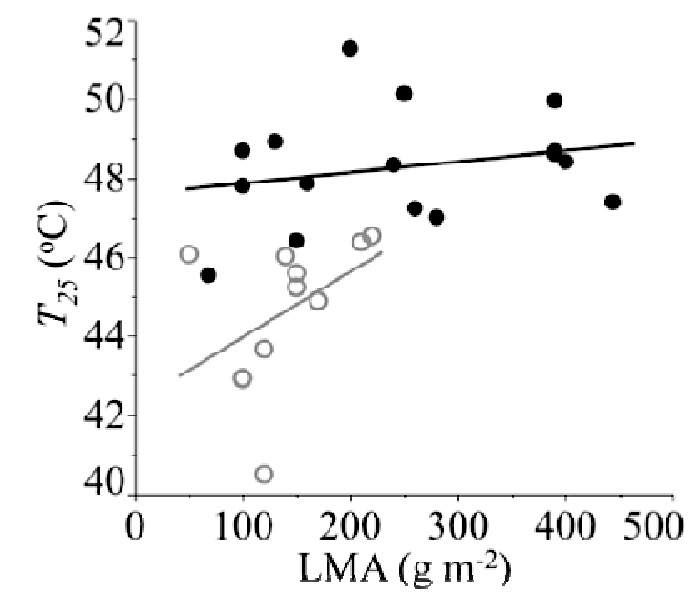

(c)

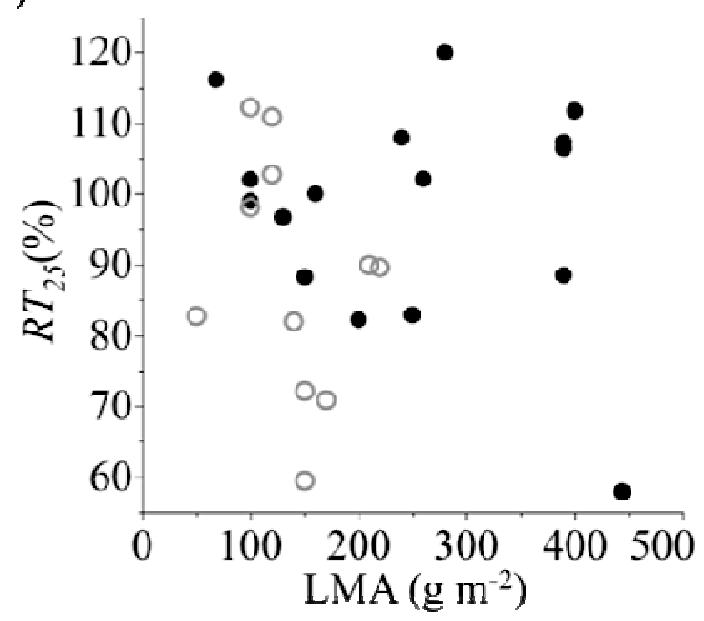

(b)

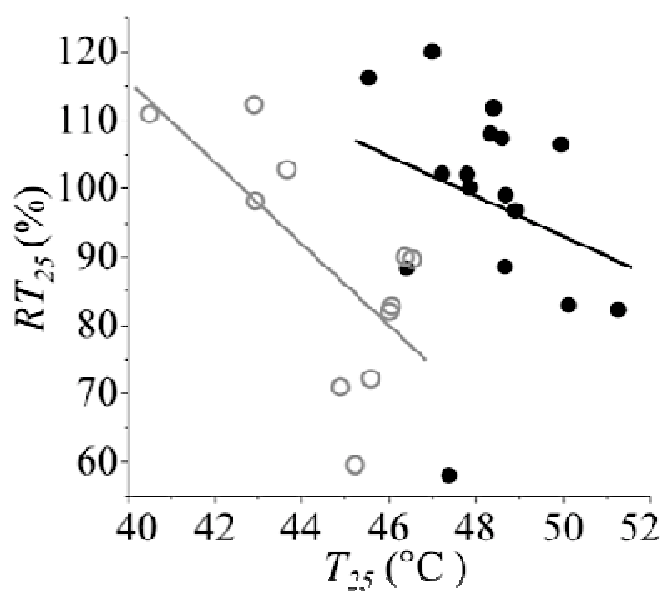

- Desert

- Montane

Figure 4. The relationships between $T_{25}, R T_{25}$, LMA, and environment for 16 desert and 11 montane species. Shown are the linear regression lines representing significant relationships for desert and montane species. (a) The relationship between $T_{25}$ and LMA after accounting for environment $\left(F_{2,24}=17.5, P<0.05\right)$. (b) The relationship between $R T_{25}$ (\% Recovery of PSII at $T_{25}$ ) and $T_{25}$ after accounting for environment $\left(F_{2,24}=4.8, P\right.$ $<0.05)$. (c) Scatterplot of $R T_{25}$ and LMA showing no significant relationship $\left(F_{2,24}=1.8\right.$, $P>0.05)$. 


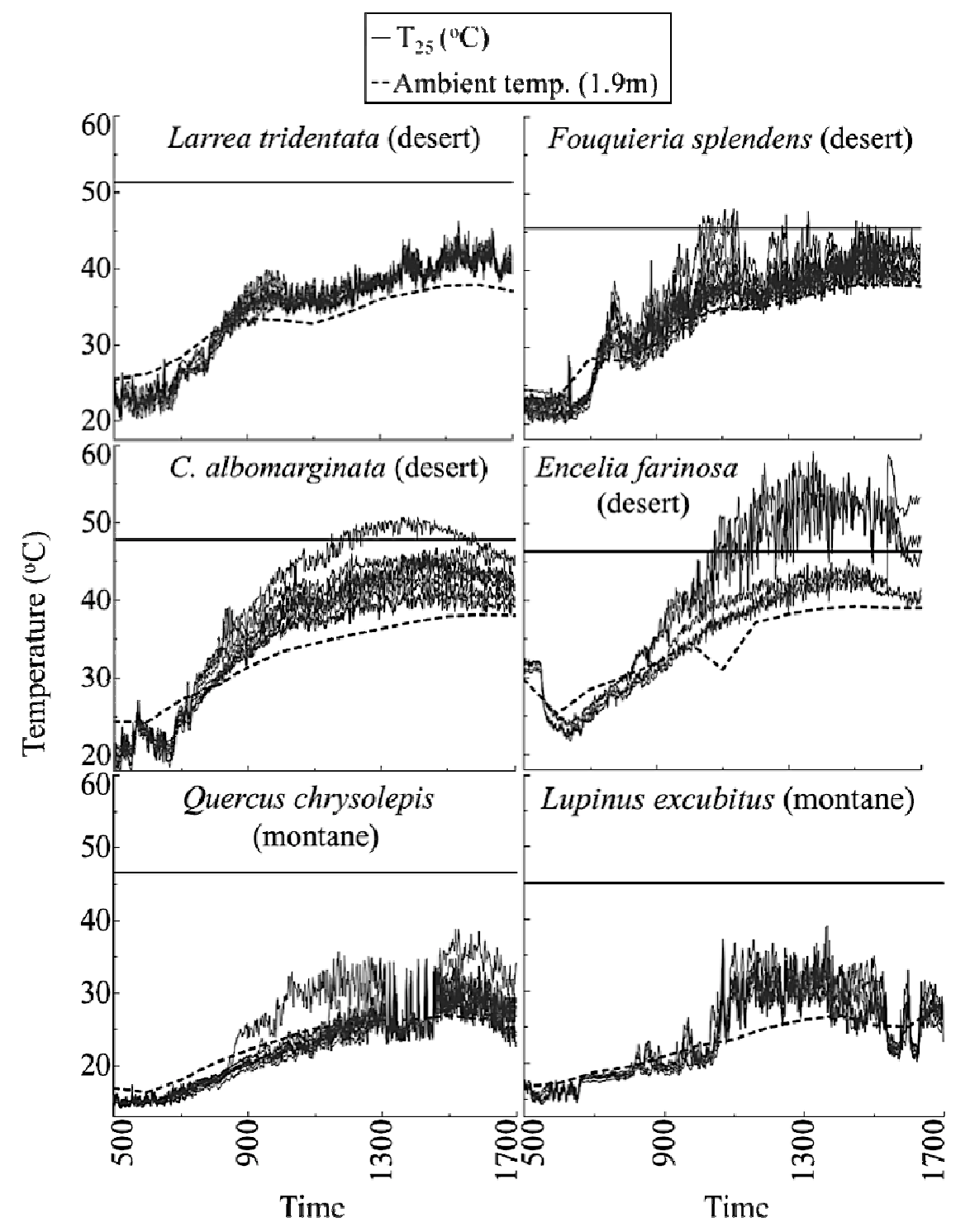

Figure 5. Leaf temperature profiles for six species. Leaf temperatures for separate leaves at different distances from ground were monitored every minute from 05:00 to 17:00 hours. The dashed black line represents the mean hourly high air temperature at $1.9 \mathrm{~m}$ from ground as recorded by a nearby weather station. The solid black line represents thermal tolerance $\left(T_{25}\right)$ and is defined as the temperature at which PSII efficiency $\left(\Delta F / F_{M}\right)$ drops by $25 \%$ after experimental heat stress. 


\section{References}

Aro, EM, McCaffery S, Anderson, JM. 1994. Recovery from Photoinhibition in Peas (Pisum sativum L.). Acclimated to Varying Growth Irradiances (Role of D1 Protein Turnover). Plant Physiology 104: 1033-1041.

Baker NR. 2008. Chlorophyll fluorescence: a probe of photosynthesis in vivo. Annual Review of Plant Biology 59: 89-113.

Bilger HW, Schreiber U, Lange OL. 1984. Determination of leaf heat resistance: comparative investigation of chlorophyll fluorescence changes and tissue necrosis methods. Oecologia 63: 256-262.

Buchner O, Karadar M, Bauer I, Neuner G. 2013. A novel system for in situ determination of heat tolerance of plants: first results on alpine dwarf shrubs. Plant Methods 9:7.

Curtis EM, Leigh A, Rayburg S. 2012. Relationships among leaf traits of Australian arid zone plants: alternative modes of thermal protection. Australian Journal of Botany 60: 471-483.

Derocher AE, Helm KW, Lauzon LM, Vierling E. 1991. Expression of a conserved family of cytoplasmic low-molecular-weight heat-shock proteins during heat stress and recovery. Plant Physiology 96: 1038-1047.

Downton WJS, Berry JA, Seemann JR. 1984. Tolerance of Photosynthesis to High Temperature in Desert Plants. Plant Physiology 74: 786-790.

Ehleringer JR, Mooney HA. 1978. Leaf Hairs: Effects on Physiological Activity and Adaptive Value to a Desert Shrub. Oecologia 37:183-200. 
Harding SA, Guikema JA, Paulsen GM. 1990. Photosynthetic decline from high temperature stress during maturation of wheat. Plant Physiology 92: 654-658.

Havaux M, Greppin H, Strasser R. 1991. Functioning of photosystem I and II in pea leaves exposed to heat stress in the presence or absence of light. Planta 186: 88-98.

Havaux M. 1993. Rapid photosynthetic adaptation to heat stress triggered in potato leaves by moderately elevated temperatures. Plant, Cell \& Environment 46: 461-467.

Heinrich Krause G, Winter K, Krause B, Jahns P, García M, Aranda J, Virgo A. 2010. High-temperature tolerance of a tropical tree, Ficus insipida: methodological reassessment and climate change considerations. Functional Plant Biology 37: 890-900

Housman DC, Price MV, Redak, RA. 2002. Architecture of coastal and desert Encelia farinosa (Asteraceae): consequences of plastic and heritable variation in leaf characters. American Journal of Botany 89: 1303-1310.

IPCC. 2007. Parry ML, Canziani OF, Palutikof JP, van der Linden PJ, Hanson CE, eds. Climate Change 2007: Impacts, Adaptation and Vulnerability. Contribution of Working Group II to the Fourth Assessment Report of the Intergovernmental Panel on Climate Change. Cambridge, UK, 7-22: Cambridge University Press.

Jones PD, Osborn TJ, Briffa KR. 2001. The Evolution of Climate Over the Last Millennium. Science 292: 662-667.

Jump AS, Peñuelas J. 2005. Running to stand still: adaptation and the response of plants to rapid climate change. Ecology Letters 8: 1010-1020. 
Knight CA, Ackerly DD. 2002. An ecological and evolutionary analysis of photosynthetic thermotolerance using the temperature-dependent increase in fluorescence. Oecologia 130: 505-514.

Knight CA, Ackerly DD. 2003. Evolution and plasticity of photosynthetic thermal tolerance, specific leaf area and leaf size: congeneric species from desert and coastal environments. New Phytologist 160: 337-347.

Krause GH. 1994. Photoinhibition induced by low temperatures. In: Baker NR, Bowyer JR, eds. Photoinhibition of photosynthesis from molecular mechanisms to the field. Oxford, UK: Bios Scientific Publishers, 331-348.

Leigh A, Sevanto S, Ball MC, Close JD, Ellsworth DS, Knight CA, Nicotra AB, Vogel S. 2012. Do thick leaves avoid thermal damage in critically low wind speeds? New Phytologist 194: 477-487.

Loarie SR, Carter BE, Hayhoe K, McMahon, S, Moe R, Knight CA, Ackerly DD. 2008. Climate Change and the future of California's Endemic Flora. PLoS ONE 3: e2502.

Marutani Y, Yamauchi Y, Kimura Y, Mizutani M, Sugimoto Y. 2012. Damage to photosystem II due to heat stress without light-driven electron flow: involvement of enhanced introduction of reducing power into thylakoid membranes. Planta 236: 753-761.

Méthy M, Gillon D, Houssard C. 1997. Temperature-induced changes of photosystem II activity in Quercus ilex and Pinus halepensis. Canadian Journal of Forest Research 27: $31-38$. 
Nath K, Phee B-K, Jeong S, Lee SY, Tateno Y, Allakhverdiev SI, Lee C-H, Nam HG. 2013. Age-dependent changes in the functions and compositions of photosynthetic complexes in the thylakoid membranes of Arabidopsis thaliana. Photosynthesis Research 117: 547-556.

Paradis E, Claude J, Strimmer K. 2004. APE: analyses of phylogenetics and evolution in R language. Bioinformatics 20: 289-290.

Parmesan C, Yohe G. 2003. A globally coherent fingerprint of climate change impacts across natural systems. Nature 421: 37-42.

Roden JS, Pearcy RW. 1993. The effect of flutter on the temperature of poplar leaves and its implications for carbon gain. Plant, Cell \& Environment 16: 571-577.

Schreiber U, Armond PA. 1978. Heat-induced changes of chlorophyll fluorescence in isolated chloroplasts and related heat-damage at the pigment level. Biochimica Biophysica Acta 502: 138-151.

Seemann JR, Downton WJS, Berry JA. 1979. Field studies of acclimation to high temperature: Winter ephemerals in Death Valley. Carnegie Institute of Washington Year Book 79: 157-162.

Seemann JR, Berry JA, Downton WJS. 1984. Photosynthetic Response and Adaptation to High Temperature in Desert Plants: A Comparison of Gas Exchange and Fluorescence Methods for Studies of Thermal Tolerance. Plant Physiology 75: 364-368.

Van Devender TR. 1990. Late Quaternary vegetation and climate of the Sonoran Desert, United States and Mexico. In: Betancourt JL, Van Devender TR, Martin PS, eds. Packrat Middens: The Last 40,000 Years of Biotic Change. Tucson, USA: University of Arizona Press, 134-165. 
Vogel S. 2009. Leaves in the lowest and highest winds: temperature, force and shape. New Phytologist 183: 13-26.

Walker JB, Sytsma KJ, Treutlein J, Wink M. 2004. Salvia (Lamiaceae) is not monophyletic: Implications for the systematics, radiation, and ecological specializations of Salvia and tribe Mentheae. American Journal of Botany 91: 1115-1125.

Walther G-R, Post E, Convey P, Menzel A, Parmesan C, Beebee TJC, Fromentin J-M, Hoegh-Guldberg O, Bairlein F. 2002. Ecological responses to recent climate change. Nature 416: 389-395.

Walther G-R. 2003. Plants in a warmer world. Perspectives in Plant Ecology, Evolution and Systematics 6: 169-185.

Weiss E, Berry JA.1988. Plants and high temperature stress. In: Long SP, Woodward FI, eds. Plants and temperature. Cambridge, UK: The Company of Biologists Limited, 329346.

Yamane Y, Kashino Y, Koike H, Satoh K. 1997. Increases in the fluorescence Fo level and reversible inhibition of Photosystem II reaction center by high-temperature treatment in higher plants. Photosynthesis Research 52: 57-64.

Yamane Y, Kashino Y, Koike H, Satoh K. 1998. Effects of high temperatures on the photosynthetic systems in spinach: Oxygen-evolving activities, fluorescence characteristics and the denaturation process. Photosynthesis Research 57: 51-59.

Yamane Y, Shikanai T, Kashino Y, Koike H, Satoh K. 2000. Reduction of QA in the dark: another cause of fluorescence $F_{\mathrm{o}}$ increases by high temperatures in higher plants. Photosynthesis Research 63: 23-34. 